\title{
End of the trail: Los últimos pastores roncaleses en las montañas de Nevada (EE.UU.) ${ }^{1}$
}

\author{
End of the Trail: Last Shepherds of Roncal \\ in the Mountains of Nevada (USA)
}

\author{
Pablo Orduna Portús \\ Grupo Red Cultural - Kultursarea. \\ Pamplona
}

Nai dionak anixko ekusi bëar du mundutik ebli.

[El que quiere ver mucho debe andar por el mundo]

Proverbio roncalés

\section{RESUMEN}

El presente artículo es el resultado de un proyecto dirigido a investigar la etnografía de aquellos roncaleses que vivieron el fenómeno de la emigración hacia EE. UU. en el Estado de Nevada. El trabajo expondrá, de manera comparativa, el desarrollo del proceso de aculturación en aquellos que llegaron para trabajar como pastores y finalmente se asentaron allí. El trabajo de campo etnográfico y la labor bibliográfica demuestran modificaciones de rituales sociales a raíz del contacto entre dos culturas diferentes. Por un lado, examinamos cómo el amoldamiento en un espacio de frontera cultural creó nuevas identificaciones tradicionales con respecto al concepto de pertenencia. A su vez, de forma particular, podemos observar y revisar lo que aquellos cambios significaron para el devenir personal de los encuestados. Por otro lado, mediante un análisis etnohistórico, alcanzamos a comprender el motivo por el que el territorio de Nevada se convirtió en uno de los enclaves principales de asentamiento de la comunidad vasca en el Oeste norteamericano. Las transformaciones económicas y culturales acaecidas en su seno se interpretan en la investigación desde los puntos de partida de límite social y aculturación.

Palabras clave: Valle del Roncal, Nevada, Pastoreo, Emigración, Aculturación, Frontera cultural.

\footnotetext{
${ }^{1}$ Proyecto de investigación [Estudio etnológico de una sociedad pirenaica fuera de su entorno comunitario original. Presencia familiar y pastoril roncalesa en el Oeste norteamericano] financiado en 2010 por el programa Grants for Research Begoña Aretxaga Memorial del Center for Basque Studies de la Universidad de Nevada, Reno. Agradezco a Agustín de Miguel Orduna y Nicolás Pérez de Miguel su disposición a participar como informantes encuestados; a los profesores Xabier Irujo y Sandra Ott, a Kate Camino y a otros miembros de la U. de Nevada su apoyo, sugerencias y los medios que pusieron a mi servicio en esta investigación. Mil gracias también a las hermanas Nina y Sarah Porzucky por su inestimable ayuda en la intendencia de esos días. Por otro lado, quisiera agradecer su compañía en dichas tierras de desierto a mi mujer Ester, mi hijo Daniel y el fruto de aquella experiencia, mi hija Leire Euria. Eskarrik anitx oroer.
} 


\section{SUMMARY}

The project presented here was directed to research and investigate the ethnography of Roncal people that lived the phenomenon of the emigration to USA in the state of Nevada. The final work will set out, in a comparative manner, the development of the acculturation process in those human communities that arrived to work like shepherds and finally settled over there. Ethnographic fieldwork and bibliographic checking showed modifications of social rituals as a result of contact between two different cultures. On the one hand the new cross-border relationships have created changes in the traditional identifications of the concept of membership inside an ethnic or peer group and particularly what those changes meant. But on the other hand, by means of historical ethnology, is achieved to comprise the reason by which the territory of Nevada turned into one of the main enclaves of settlement of the Basque community in the North American West. These border meetings and practices interpret the concept of limit and identify itself with the same local culture located on either side of the mountains. The economic and cultural transformations become in its community bosom, will be interpret like the point of departure for this reflection stems from the question of how critically review their social limit and acculturation.

Key words: Roncal Valley, Nevada, Shepherding, Emigration, Acculturation, Cultural Border.

Una templada noche del Pirineo navarro, Agustín de Miguel Orduna, natural de Casa Barreña, junto a su primo Nicolás Pérez de Miguel, natural de Casa Malangorria, bajaron por las empinadas calles del barrio de Irigoine en Uztárroz - Uztarroze Goiena (Valle de Roncal - Erronkari'ko Ibaxa) en dirección a la taberna El Requeté (actual Bar Latsa) situada junto al río. Nacidos en 1935 y 1939, con 30 años se disponían a celebrar con sus quintos su partida a la mañana siguiente hacia Nevada (NV), Estados Unidos. Ambos habían trabajado ya en los bosques del valle y de la vecina Basaburüa zuberotarra (Francia), como almadieros. Así mismo, siguiendo los rasgos culturales de una larga tradición de la comarca, lo habían hecho como pastores, siendo "repatanes" desde los 14 años (Barandiarán 1953-1957: 7; Barandiarán y Manterola 2000: 73-75).

Entre quienes estaban casados, tenían descendencia o parientes en el mismo oficio, existió la tendencia a trasladar al otro lado del océano los vínculos familiares, y gran parte de los emigrantes lo hizo viajando junto a parientes (Douglas 1986: 411). Este fue el caso de nuestros protagonistas de Uztarroze. En mayo de 1966, ambos roncaleses, Agustín y Nicolás, habían visto llegar el momento de dejar su tierra natal y comenzar un viaje hasta las del condado de Elko (NV). Su destino inicial en el Oeste norteamericano no era sino trabajar como pastores e intentar ganar algo de dinero para regresar y establecerse definitivamente en su pueblo o en Pamplona. Sin embargo, esta marcha iba a convertirse en un viaje sin retorno (por lo menos definitivo) y en su inmersión en una nueva sociedad con sus propias costumbres y valores ${ }^{2}$. Qui-

\footnotetext{
${ }^{2}$ Actualmente se está trabajando en el estudio de la marcha de un centenar de izabarres a principios del siglo XX. Todos ellos se asentaron en el estado norteamericano de Nuevo México con el mismo objetivo que los vecinos de Uztarroze entrevistados. Para el análisis de su trayectoria, se cuenta con el apoyo de la Asociación Pro Isaba \& New Mexico y de su presidente Josep Oms Piera. Estos roncaleses originarios de Isaba - Izaba se asentaron en las localidades de Vaughn (Guadalupe County), Encino (Torrance County) y Lamy (Santa Fe County), dando origen a una sólida comunidad con abundante descendencia. Un caso parecido se dio tiempo atrás en el lugar denominado Rancho Valle Roncal y sito en el municipio de Hueytamalco del Estado de Puebla, ya al otro lado del Río Grande y en territorio mexicano.
} 
zás, el día de la partida resonaran en sus mentes palabras como las que en 1643 recogió Axular (2003: 83) en este pasaje de su Gero:

Gizon batek, bere herritik kanpora Indietara edo bertze lekbu urrun batetara partitzen denean, eta oraiño bere berriko agerrian, komarketan eta terminoetan denean, maiz behatzen du gibelat, bere herriko mendietarat. Baiña aitzina iraganez gero, bere herria eta berriko lurrak bistatik galduz gero, itzultzen da bertze alderat, ioan behar duen eta dohan lekhu hartarat: eta han aldiz, bere begiak, eta gogoa ere ibentzentu.

[Cuando un hombre sale de su país a las Indias o a otra tierra lejana y aún se encuentra a la vista de su pueblo, en la comarca o términos del mismo, se vuelve con frecuencia a mirar atrás, hacia los montes de su tierra. Pero prosiguiendo adelante, una vez perdidos de vista su pueblo y las tierras del mismo, se vuelve al otro lado, hacia el país a que se dirige, y pone en él sus ojos y también su voluntad].

Hay un dicho roncalés que dice "lotsa dionak betik dâma begi bat atziri beira. Es decir, que quien tiene miedo, siempre lleva un ojo mirando atrás. Sin embargo, este no fue el caso de nuestros protagonistas.

Con objeto de acercarnos a la nueva realidad que vivieron ambos roncaleses, se diseñó un cuestionario base destinado a aplicárselo a los informantes en su tierra de acogida. En definitiva, se trataba no sólo de estudiar su caso, sino también de plantear nuevas vías de investigación que nos ayudasen a completar el estudio etnográfico de la realidad cultural del valle, tanto dentro, como fuera de sus mugas. Además de un apartado inicial de recogida de datos personales de los informantes, la encuesta se componía de cuatro epígrafes más.

Los primeros se referían a su llegada a América, sus datos familiares en el nuevo lugar de residencia y las relaciones mantenidas con los parientes en su tierra natal, el proceso de aculturación e integración en Estados Unidos y el desarrollo de su vida

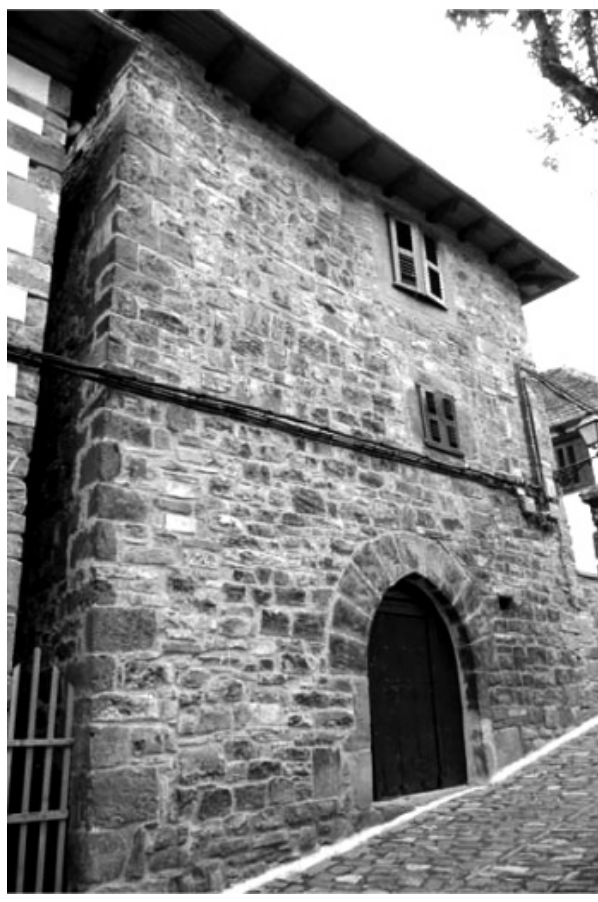

Figura 1.-Casa Barreña de Uztárroz, Valle de Roncal. 2010. Foto de Pablo Orduna Portús. a posteriori. En el penúltimo punto se trataron cuestiones relativas a su asimilación del nuevo modo de vida (American way of life), el asociacionismo con grupos étnicos afines, sus actividades y relaciones con otros emigrantes, el mantenimiento de costumbres propias y la asimilación de nuevas, el uso de los diferentes idiomas y su visión del Valle desde una perspectiva lejana en tiempo y espacio. En el último apartado, una primera sección recogía sus primeras vivencias como pastores en los montes de NE de Nevada. Finalmente, el apartado se refería a cuestiones acerca de su establecimiento definitivo en la costa oeste, junto a la bahía de San Francisco (San Fran- 
cisco Bay Area). En este nivel de la encuesta se revisaron los motivos que originaron este traslado y sus apreciaciones personales de su experiencia como roncaleses en América (carencias, ventajas, sueños, modos de vida).

\section{¿POR QUÉ PARTIR Y POR QUÉ A NEVADA? SWEET PROMISED LAND?}

Cuando Agustín y Nicolás prepararon su viaje ya sabían que su destino inicial eran las montañas del norte del Estado de Nevada. Desde finales del siglo XIX, este territorio fue testigo de la conformación de la figura del pastor vasco en el Great Basin, o Gran Cuenca desértica del Oeste norteamericano. Ya en 1871, el vasco francés Jean Garat y el vasco español Pedro Altube (conocido como el Father of Basques in America), se trasladaron desde California con objeto de establecer en el noroeste, en Independence Valley, el llamado Spanish Ranch dedicado a la explotación ovejera.

Quizá, tanto la antropología, como la historia norteamericana han pasado por alto el papel de todas estas gentes que desarrollaron una próspera gestión de este desértico espacio. Entre ellos destacaron mineros, dueños de casinos y sobre todo pastores y ganaderos que, con sus ovejas, alimentaron a los primeros. La gran cantidad de tierras públicas en Nevada favorecía su desarrollo con bajos costes, y los animales aguantaban bien la crudeza del invierno y del verano. Tan sólo se produjeron conflictos con los rancheros, que veían peligrar la disponibilidad de la escasa agua que llegaba al territorio. A la larga, estos problemas supusieron nuevas regulaciones y limitaciones de los prados comunales libres de dueño ${ }^{3}$.

En cualquier caso, la historia de las ovejas en el Oeste comenzó en el año 1841 cuando llegaron las primeras cabezas al territorio. Fueron llevadas desde Nuevo México con destino a California para alimentar a los mineros durante el gold rush o fiebre del oro de 1848 (Alday 1999: 150-173). De esta forma, en 1852, Richen L. "Uncle Dick" Wootton transportó 9.000 ovejas mexicanas (churras) hasta el noroeste del Valle de Sacramento en California. Ese mismo año C. D. Jones instalaría en el valle de Carson (NV) su propia explotación ovina. La industria se vio beneficiada en el caso de $\mathrm{Ne}$ vada (The Silver State) por las nuevas minas abiertas y la llegada del ferrocarril transcontinental en 1869. Ya en 1853, C. D. Parker estableció en el condado de Douglas (NV) sus propias ovejas para alimentar a los mineros del filón de plata hallado en Comstock Code (Pérez de Arenaza et al. 1991: 342; Zubiri 1998: 14). A éste le seguiría el prusiano H. F. Dangberg, quien levantaría un rancho al este del río Carson. Además introdujo el cultivo de la alfalfa en el Estado, importándola desde Chile ("trébol chileno"). En 1864, Nevada se había convertido tanto en un Estado más de la Federación, como en la Sweet Promised Land para muchos de estos pastores (Laxalt

\footnotetext{
${ }^{3}$ En 1931, se restringió el número de ovejas que podrían pastar en estos espacios. En 1934 una gran sequía obligó a los ganaderos a buscar nuevos pastos, pero la aprobación de la Taylor Grazing Act y las restricciones que conllevaba limitó más el pastoreo y sobre todo su modalidad de ovejero nómada (Zubiri 1998: 19). Desde ese momento, los antiguos pastos libres quedarían bajo supervisión y control del Servicio Estatal de Bosques (USFS - United States Forest Service) que regularía su disfrute (Totoricagüena 2004a: 62). Estos problemas se vieron acrecentados por las limitaciones impuestas por el USFS, dando lugar a grandes conflictos en 1906 y provocando tensión entre los pastores y los agentes del servicio federal (Douglass y Bilbao 1986: 352-357).
} 
1957). La madrastra del gobernador, emocionada, describía el país de la siguiente manera:

It is strange that the Great Seal of the State of Nevada shows no sheep. Somehow, down the years, ranching, the key to prosperity through most of Nevada history has been taken for granted or overlooked completely. Certainly, if the Seal portrays the resources of the state it should include a sheep ${ }^{4}$.

Y es que en 1876, se había fundado la asociación ganadera de Nevada (Nevada State Livestock Association -NSLA-), cuyos miembros juntaban unas 49.000 ovejas. Siete años después, el escocés Juan G. Taylor, mercader de corderos y lanas, se había convertido en el "barón" ganadero más importante del Estado, poseyendo 250.000 acres y arrendando medio millón más para la cría de sus ovejas. Él fue el primero en reclutar pastores vascos y con el tiempo algunos de ellos, como los hermanos Saval, fundarían sus propios negocios ovejeros. A principios del siglo XX, en 1905, se importaron desde Inglaterra cien carneros de raza Lincoln. Ésta es la oveja más grande de las islas británicas y desarrolla una tupida lana apropiada para climas tan extremos como el de Nevada. Por ello, muchos de sus ejemplares se han empleado para mejorar la calidad de la lana y cría de otras razas. La idea de su introductor, Patrick Flanigan, supuso la formación de un nuevo tipo de oveja Rambouillet americana.

En las dos siguientes décadas la industria agropecuaria siguió prosperando y se especializó en la cría de corderos para la alimentación. Tales cabezas obtenían salida en el mercado estable que suponía la cada vez más populosa California. Aunque la inmigración vasca a los Estados Unidos fue casi suprimida como consecuencia de la National Origins Quota Act de 19215, siguieron llegando todavía pastores desde Vasconia, tanto a través de los cauces legales, como sobre todo por medio del jumping ship o entradas irregulares (Zubiri 1998: 18). No obstante, tras la Segunda Guerra Mundial, faltaban pastores para esta industria ganadera, que comenzaba a encontrarse en una severa crisis. Por ello, entre 1942 y 1961, en el Congreso se aprobaron las Sheepherder Laws. Esta nueva legislación permitió que alrededor de 383 vascos obtuvieran la residencia permanente. Esto, unido a las leyes denominadas Sheepherders Bills - 1952 Public Law 307-, apoyadas por el senador de Nevada Patrick McCarran, atrajo a estos áridos territorios a multitud de emigrantes desde ambas vasconias, peninsular y continental. A través de una immigration act se autorizó la entrada de una cuota de 500 Spanish Sheep Herders u ovejeros españoles.

Por otra parte, los ganaderos ovinos del Oeste se agruparon en diferentes asociaciones que permitieran la subsistencia de sus rebaños. En 1942 surgía la Nevada Range

\footnotetext{
${ }^{4}$ Cit. en http://knowledgecenter.unr.edu/sheepherders/chronology.html. (Consultada 1-11-2012).

${ }^{5}$ Esta normativa legal quería limitar la llegada de emigrantes desde el sur y el este del continente europeo. Según dicha ley, de España sólo sería aceptada una cuota anual de 131 súbditos y de Francia, alrededor de las 4.000 personas. En general en Nevada, al contrario que en California, había más vasco-españoles que vasco-franceses. Entre ellos predominaban los altonavarros; seguidos de los bajonavarros de Iparralde (Alday 1999: 150-173; Bilbao 1982: 163 y ss.). Por su parte, los vizcaínos se asentaron más en Idaho, mientras que alaveses y guipuzcoanos no están presentes casi en la región. Todo ello es un reflejo más de la importancia que tuvo en el Oeste este subgrupo pirenaico durante el desarrollo de la industria ganadera de carácter ovino (Totoricagüena 2004a: 28).
} 
Sheep Owners Association, con Juan Dangberg como presidente. Nueve años más tarde era creada la California Range Association para hacer frente a la creciente crisis en el sector ${ }^{6}$. En 1966, esta agrupación cambió de nombre, pasando a denominarse Western Range Association -WRA- y a unificar a todos los productores del Oeste. En ese año, 1.283 pastores estaban bajo contrato de dicha asociación por tres años de duración. En 1970 se dio el pico más alto de pastores contratados en esta área con 1.500 bajo la WRA, siendo el 90\% vascos. Sin embargo, en 1976, el número de pastores se había reducido a la mitad y sólo 106 eran vascos. Esto nos refleja claramente que la hasta entonces próspera industria ovina, estaba ya en decadencia y muchos de sus operarios buscaban nuevas formas de subsistencia en EE. UU

En el noroeste de Nevada, exactamente en la localidad de Winnemucca (Humboldt County) y en los montes de Tuscarora (Elko County), encontrarán trabajo y asentamiento algunas de estas nuevas oleadas de pastores inmigrantes. Muestra de ello son la multitud de "arborglifos" que se pueden observar tallados en los álamos temblones, como los de la cordillera de Peavine en la parte septentrional de Nevada (Zubiri 1998: 245-248). De ellos Joxe Mallea-Olaetxe (2000) ha señalado que suponen algo más que una simple manifestación de la "loneliness, isolation, or boredom" del pastor allí destinado. Como dicen William A. Douglass y Richard H. Lane (1985: 63), estas expresiones artísticas tan rústicas pueden considerarse la forma en la que el solitario cuidador de los rebaños

humanizes an otherwise unrelentingly pristine natural environment. Thus, whether wandering through an aspen grove or contemplating a stone monument he enjoys a certain illusion of not being alone. Rather, despite his solitude a man can commune with the ghosts of past generations and enjoy some small sense of purpose as he leaves his own mark as a legacy for future herders.

Aunque fue la situación política y económica de Europa y España lo que motivó a la mayoría de los emigrantes de Vasconia a ir a América en plena mitad del siglo XX, esta opción también se mostraba atractiva para todos aquellos jóvenes ávidos de aventura. Muchos, como nuestros dos protagonistas, no conocían siquiera las condiciones reales que se encontrarían en aquellas tierras. Por eso, muchos regresaron tras pasar los tres años de contrato. Por el contrario, otros decidieron quedarse y forjarse una nueva vida al otro lado del Atlántico, aunque ésta no fuera su idea original. Podemos decir que estos últimos recibieron la "call to adventure" mencionada por Campbell (1973: 58). Según el autor, esta llamada "signifies that destiny has summoned the hero and transferred his spiritual center of gravity from within the pale of his society to a zone unknown".

\footnotetext{
${ }^{6}$ Para agravar aún más la situación, el invierno de 1949 fue tan duro que la fuerza aérea estadounidense tuvo que poner en marcha la llamada Operation Haylift destinada a acarrear con aviones de carga hasta 525 toneladas de alfalfa para poder alimentar a unas 10.000 cabezas de ganado ovino en el norte de Nevada y Utah, y los estados de Colorado, Nebraska y Dakota del Norte (Paris 1971: 157-170). Así nos lo describe Clel Georgetta (1972: 338): "A flying boxcar with four tons of baled hay on board flew over Tom Thurnal's place and tried to drop eight bales of hay in his corral. On the plane's first pass, some bales the plane dropped took off the porch of the house. On the next pass the heavy bales falling out of the sky smashed the wash house with his wife's new washer in it. Tom got on a saddle horse, rode to McGill, called 'Operation Hay Lift'”.

${ }^{7}$ http://knowledgecenter.unr.edu/sheepherders/default.htm. (Consultada 2-11-2012).
} 
El 10 de mayo de 1966 los dos primos de Uztarroze aterrizaban en Nueva York. Ésta sólo era una toma de contacto inicial en su viaje. Tras pasar los controles de la aduana, tomaron otro vuelo hasta Elko (NV), haciendo antes una escala en Salt Lake City (Utah). Su primera intención era ahorrar lo suficiente como para poder volver y asentarse en Navarra. Otros emigrantes que habían retornado les habían asegurado que con lo que iban a ganar en tres años como pastores podrían comprarse un piso en Pamplona, que por aquel entonces rondaba las 250.000 pesetas.

Sin embargo, había otros motivos que marcaron el viaje a América. En su interior albergaban la esperanza de poder progresar y de lograr conocer algo más de mundo. En el Pirineo habían trabajado en pésimas condiciones laborales "picando" - talando- madera de los bosques, mal pagados y explotados. Se trataba de una región que, alejada de los focos de producción industrial, ofrecía pocas oportunidades. Como dicen ellos, "O ibas a cura o fraile o no tenías ayuda alguna para estudiar cursos superiores". Recuerdan la coplilla que decía:

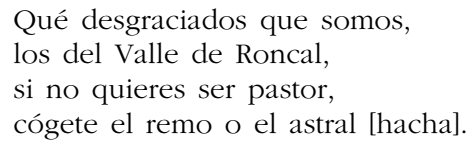

Por otra parte, hay que tener en cuenta que entonces EE. UU era tenido como el país más rico y próspero del mundo, así que tras su estancia de pastores no descartaban el quedarse y conocer algo de tan sugerentes tierras y formas de vida. Incluso pensaron que, acabado su contrato, no sería mala idea ir a Oregón para trabajar en sus bosques como leñadores.

\section{EL OFICIO DE PASTOR EN AMÉRICA: "JOB IN SOLITUDE»}

Agustín y Nicolás tomaron decididos el camino hacia el Oeste americano. Sería éste un lugar donde ser pastor, no sólo significaría aventura, sino en gran medida pertenecer a una colectividad y soportar la dureza de una nueva forma de vida. Totoricagüena (2003) señala que ésta

Basque ethnic identity in the United States remains tied to the collective past they share of sheepherding as the door opener to the United States, and even those Basques whose families never were a part of the sheep business still preserve this significant aspect to the history of Basque development in the West.

Cuando los dos vecinos de Uztarroze llegaron a Elko, su "mayordomo" -capataz de la compañía ganadera a la que se les había asignado- les alojó en el establecimiento vasco Overland Hotel, fundado en 1908 por Domingo Sabala. Se les planteó la opción de descansar algún día más o empezar a trabajar al siguiente. Ambos, desconocedores de lo duras que serían las siguientes campañas, optaron por iniciar cuanto antes su trabajo.

Como afirma Lasagabaster (2006: 83), la vida en soledad era tan dura que muchos no dudaron en marcharse a California en busca de mejores expectativas, huyendo de una desesperación permanente. Buen número de ellos se vieron afectados 


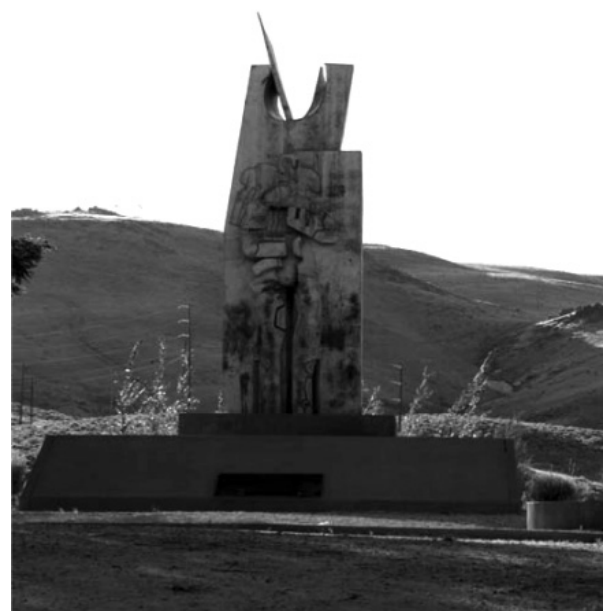

Figura 2.-Monumento al Pastor Vasco en Reno Nevada. 2010.

Foto de Pablo Orduna Portús.

de tal manera por la solitude — soledad(permanente, a excepción de los ratos de las visitas del campero que traía los víveres cada ocho días) y la incapacidad inicial de comunicación por falta de conocimiento del inglés, que deseaban marcharse ${ }^{8}$. Sólo el amor propio y la tozudez les empujaban a quedarse y a habituarse al final a ese duro régimen de vida (Ciérbide 1997: 30). En cualquier caso, el reconocimiento a su labor se dio en diferentes puntos de este extenso territorio, siendo un ejemplo de ello el monumento al pastor vasco - National Monument to the Basque Sheepherder- levantado en Reno (NV) con financiación pública americana, de la Comunidad Autónoma Vasca, del Gobierno de Navarra, de Iparralde y capital privado. En su centro se sitúa la escultura de Néstor Basterretxea llamada "Bakardade" o "Solitude" - Soledad-y realizada en 1989 (Urrutia 1992: 45-47)9.

Sin embargo, a pesar de esa temible soledad, sólo entre 1943 y 1949 la Asociación de Criadores de Ovejas del Este de Nevada atrajo a más de 100 pastores, que llegaban al país bajo las imposiciones del estatus de visitantes temporales de la Ley de Inmigración Federal de 1924. En 1963 la Oficina de Inmigración autorizó la contratación de inmigrantes que llegasen para trabajar como pastores por tres años. Ahora bien, si se marchaban después, se les permitía regresar de forma intermitente para continuar con esa profesión en suelo norteamericano y finalmente algunos lograban cumplir los requisitos para obtener la ciudadanía (Douglass y Bilbao 1986: 380 y 388-389).

Los patrones en ocasiones no cumplían con lo acordado y no pocas veces dejaban de pagar el sueldo o engañaban a los recién llegados con las cantidades de pago.

\footnotetext{
${ }^{8}$ Los víveres se los llevaban los camperos —asistentes de los mayorales- en una reata de mulos o en ranchera. A veces, también les llevaban pienso para las ovejas, así como algo de comida para los caballos y los perros. Por otro lado, la carne que comían era de corderos sacrificados de sus propios rebaños o de algún animal que cazaban con el rifle y las pocas balas que les habían proporcionado para defender el ganado de los coyotes.

${ }^{9}$ El aislamiento que sufrían quedó bien reflejado en una campaña publicitaria de la compañía de telefonía móvil AT\&T que fue emitida en 2001. En ella aparecía el ganadero de Goizueta (Navarra) Dionisio Txoperena, "Dio", afincado desde 1973 en California. Los spots se centraban en la figura de un pastor de ovejas que lograba romper su incomunicación en la montaña, gracias a la cobertura telefónica que ofrecía esta empresa. Los anuncios tuvieron tal repercusión y éxito que su protagonista rodó diferentes episodios durante dos años y se hizo popular, tanto a ese lado del Atlántico, dentro de la comunidad vasco-norteamericana como en su tierra natal, siendo conocido como "el pastor de AT\&T".
} 
A pesar de la solidaridad colectiva que solían demostrarse entre ellos, en ocasiones los vascos preferían patronos angloamericanos (WASP) en vez de originarios de su tierra. Esto se debía a que la explotación se producía de forma más habitual por parte de sus paisanos (Lasagabaster 2006: 83). Por ejemplo, el "mayordomo" o mayoral de Agustín y Nicolás, natural de Irurita (Navarra), quiso extorsionarles, amenazándoles con impedir que tuvieran la green card si no se quedaban más tiempo trabajando en la explotación.

En los años 60, cuando llegaron nuestros protagonistas a Nevada, la California Range Association ya se había convertido en la Western Range Association y funcionaba en el ámbito federal. Ante el fracaso del programa de pastoreo ideado en la Universidad de Brigham Young (Utah) para la formación en el oficio de norteamericanos, se optó por buscar pastores en Europa. Tras las negociaciones con el Estado español, éste exigió que los emigrantes reclutados fueran desde todas partes de la península. Al final, el proceso de selección tuvo lugar en el consulado americano en Bilbao y por eso se eligieron sobre todo pastores vizcaínos y navarros. Además, la asociación norteamericana prefería contar exclusivamente con emigrantes vascos. Finalmente, el acuerdo estableció que de cada diez operarios pecuarios vascos otro iría desde otro territorio distinto. Así mismo, el gobierno español mantuvo una posición dura en las negociaciones y el gobierno de los EE. UU. concedió dar la residencia permanente a los pastores, pasados tres años.

La Western Range Association decidió facilitar contratos de trabajo por tres años con un sueldo de 215 dólares mensuales el primer año, para llegar a cobrar 250 en el último del trienio. El cuarto año que pasaron como pastores Agustín y Nicolás la mensualidad sólo subió hasta los 270 dólares. Las cláusulas obligaban al contratado a dirigirse al lugar en que la Asociación pudiera requerirle, pagando el coste de su viaje. Una vez ahí, debería trabajar y residir en la hacienda asignada por el empleador. Durante su estancia, tenía que obedecer y cumplir con los reglamentos establecidos por el patrono. Estas normas estaban destinadas a garantizar la seguridad y la conservación en buen estado de la propiedad. Se debía trabajar en exclusiva con ese ganadero y jamás con alguien de fuera de la WRA. La Western Range adelantaba al pastor los gastos de viaje (ida y vuelta) y el contratado lo reembolsaba por medio de restricciones mensuales de su sueldo. La WRA se encargaba de la manutención del pastor en los puertos y llanos, sin cobrarle ningún gasto adicional. Para asegurar su "bienestar", un representante de la Asociación visitaría mensualmente los aposentos del empleado para asegurarse de que fueran dignos. De igual manera, le garantizaba un entierro adecuado en caso de fallecimiento durante el periodo de su empleo, contemplándose también diferentes protecciones en caso de accidentes o enfermedades. Por otra parte, se les garantizaba el regreso gratuito a su tierra de origen si el exceso de mano de obra local impidiera lograr un empleo en EE. UU ${ }^{10}$.

Estas fueron las condiciones con que los primos del Pirineo navarro llegaron al Oeste para cumplir un contrato de tres años, que verían ampliado en uno más. El viaje lo organizaron desde Elizondo (Navarra), mediante la intervención de una lugareña llamada Ana Mari que tenía contactos con la WRA. La asociación sólo les daba inicialmente el billete de ida para evitar que, una vez en suelo norteamericano, se

\footnotetext{
${ }^{10}$ http://www.euskomedia.org/aunamendi/26645/116703. (Consultada 2-11-2012).
} 
fueran por su cuenta sin cumplir el contrato. El viaje de vuelta sólo les fue reembolsado cuando obtuvieron la green card, o permiso de residencia, en 1970.

Las técnicas de pastoreo variaban en cada una de las regiones del oeste y medio oeste americano. Todas ellas seguían los patrones del clima dominante en cada zona, la geografía y la disponibilidad de pastos. Así, en el sur de Idaho, este de Oregón y norte de Nevada el ciclo de pastorear y apacentar en determinados pastos, así como el movimiento de las cabezas de ganado, era anual (Totoricagüena 2004a: 61). Como ya señalamos, en Nevada, el desarrollo de esta gran industria ovina supuso el uso de pastos abiertos, dando lugar a una casi total dependencia de las tierras públicas y a la creación de vías pecuarias entre los pastos de verano en las zonas altas y las tierras bajas desérticas en invierno (Douglass y Bilbao 1986: 318-321). Se siguió por tanto un modelo de ganadería extensiva, ya que el sistema estabulado hubiera sido imposible debido al rigor del clima ${ }^{11}$.

A pesar de las duras condiciones meteorológicas, el NE de Nevada — -northeastern corner of the state»- se convirtió en el paraíso de muchos rebaños por sus magníficos prados de hierba (Zubiri 1998: 310-329). Hay que comprender que aproximadamente el 90\% de las tierras del condado de Elko (NE de Nevada) eran de dominio público no regulado. Por ejemplo, una de sus comarcas, llamada Bruneau Country, poseía unos 700.000 acres (Lane 1977: 35 y 38) ${ }^{12}$.

Así pues, una vez asentados en la explotación ganadera de un propietario local, los recién llegados desde Europa no se quedarían estáticos en uno de los escasos núcleos de población de la Nevada septentrional. Los sheepherders (pastores), se dedicarían a movilizar los rebaños que se les asignaba, de entre 1.000 a 4.000 ovejas, en un sistema trashumante estacional. Tales desplazamientos estaban destinados a la búsqueda de pastos y lugares adecuados para afrontar los rigores de un clima tan extremo. En esta región, los recorridos pecuarios eran de más de 500 millas — 804,672 km. — desde el páramo del desierto a los pastos de las montañas. Una vez en lo alto de las sierras, los campamentos de los pastores se distanciaban en más de una milla (1,609 km.) unos de otros, lo que venía a aumentar la constante soledad (Lane 1977: 33-34).

Nuestros dos pastores, partían en solitario a los puertos con las ovejas marcadas de brea en el lomo, muescas en las orejas y pequeños cencerros. El desplazamiento se iniciaba con unas 1000 ovejas, pero se convertían a veces en el doble, al sumárseles hasta 1200 corderos nacidos a lo largo de la campaña y destinados a carne. Su destino en el verano eran unos terrenos en la frontera con Idaho, en Midas (antiguo pueblo minero abandonado), donde tenía lugar la parición. Posteriormente iban a las sierras del Humboldt National Forest cercanas a Tuscarora, que son propiedad del gobierno y están junto al pueblo de la reserva de los indios shoshones llamado Owyhee

${ }^{11}$ El Estado de Nevada mantiene un clima básicamente desértico continental. Posee dos estaciones bien marcadas, siendo sus inviernos muy fríos y largos, mientras que sus veranos son cálidos. Debido a su carácter desértico, durante todo el año registra gran variación de temperatura entre el día y la noche. Por otro lado, su parte septentrional, atendiendo a su latitud y altitud, carece casi de temperaturas medias volviéndose mucho más rigurosa que el sur del territorio.

${ }^{12}$ Sin embargo, entre un 59\% y un $80 \%$ de ellos fueron quedando paulatinamente bajo control del mencionado USFS. La compañía que contrató a nuestros entrevistados poseía ovejas también en Oregón y una amplia extensión de fincas en la frontera entre este Estado y Nevada, por lo que jamás tuvo problemas con el USFS, ni necesidad de pedir permiso alguno. 

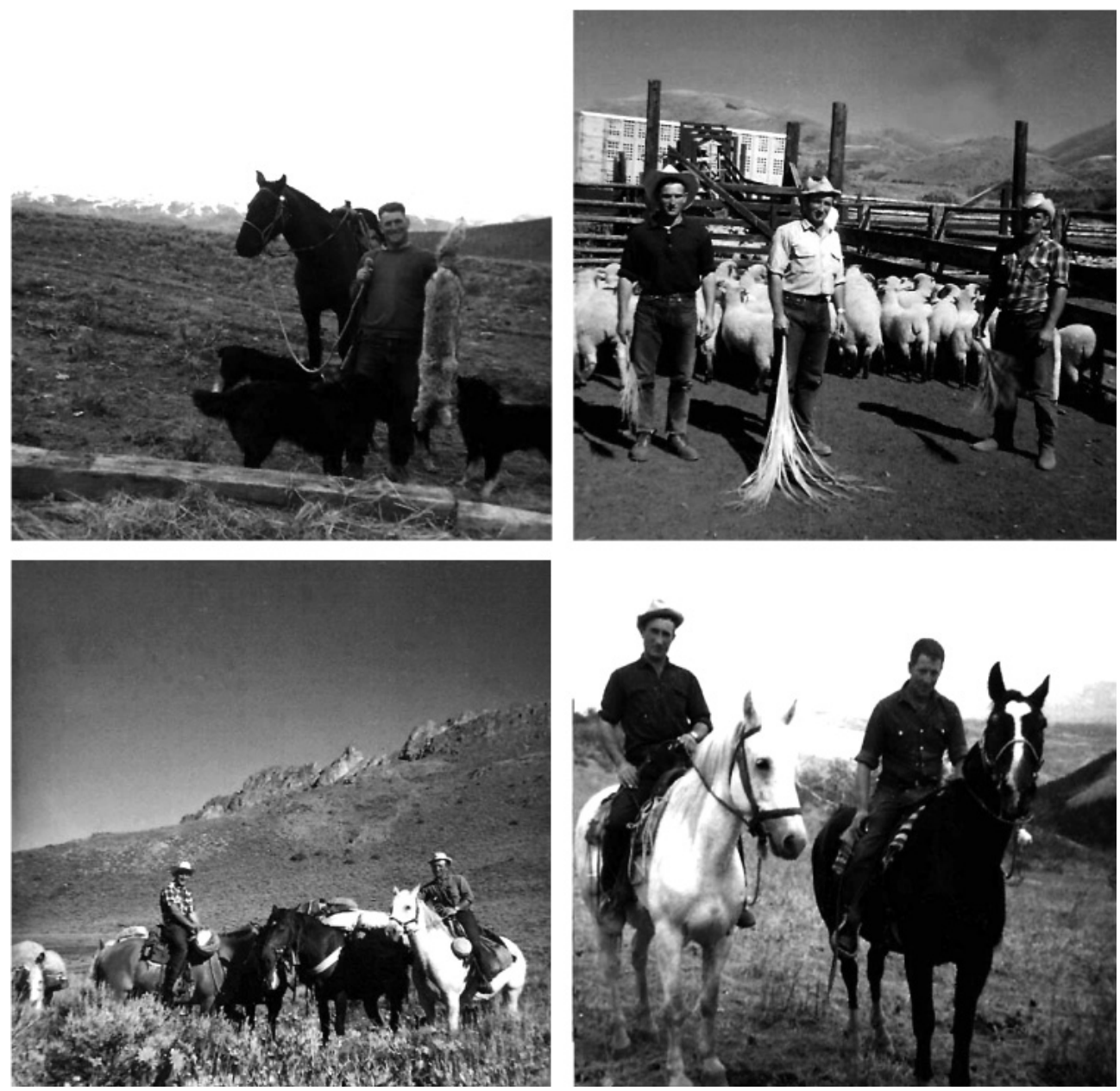

FiguRA 3.- Pastoreo extensivo en Nevada. Años 60. Fondo fotográfico de Agustín de Miguel y Nicolás Pérez.

y a la localidad de Mountain City. El correo sólo lo podían recoger a su paso por Tuscarora y siempre debían estar atentos para ver si había nieve en los páramos de los desiertos, porque si no el ganado no tendría agua para beber.

En general, el artzầ — pastor en roncalés - convertido en nómada temporal, marchaba a caballo, en solitario y con la única compañía de su atajo de ovejas y un buen perro pastor. Estos canes les ayudaban a manejar y a proteger los rebaños, y en ocasiones hasta a mantener los únicos diálogos en mucho tiempo. Durante esos largos días de caminatas y soledad, los pastores ahorraban dinero - como mucho gastaban en algún calzado, pantalones y espuma de afeitar-, leían, escuchaban radiotransistores, hacían tallas en los álamos o permanecían alerta frente a las alimañas. Los perros, como ellos, estaban siempre atentos a posibles coyotes que acecharan en las inmediaciones. 

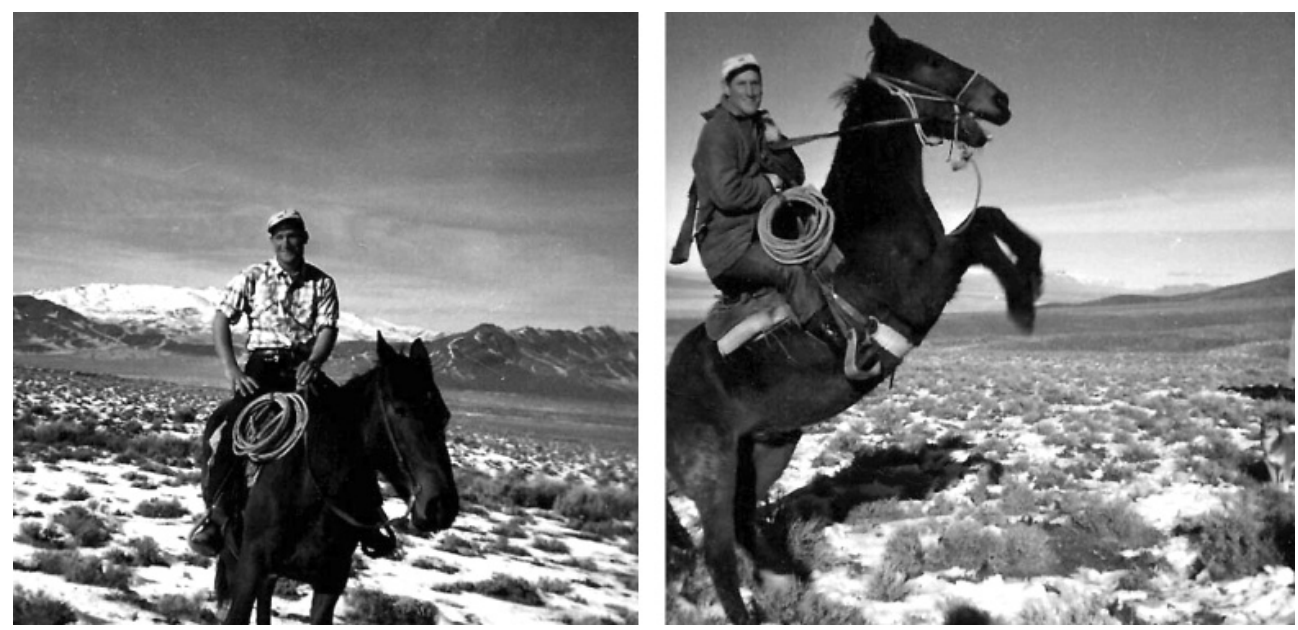

FIguRA 4.-Páramos del desierto en Nevada. Años 60. Fondo fotográfico de Agustín de Miguel y Nicolás Pérez.

I had to stay right by the sheep, especially at night. There were lots of coyotes and I wanted to save every lamb. I had almost one thousand, but I cared about each one. If I found a dead lamb, well I just started to cry (Paris 1971: 30).

Los mulos y los canes eran propiedad del patrón, pero con el tiempo, los segundos se hacían a la compañía de un ovejero al que seguían día y noche. Por ello, se desarrollaba otro tipo especial de relación de dominio y subordinación, basada en un gran sentido de la lealtad y la mutua necesidad. Tal fue esta intensa relación que en muchos casos se mantuvo hasta la muerte de uno de ellos, y algunos perros eran comprados por los pastores a los patrones cuando dejaban la hacienda (Sawyer 1971: 169-172).

Entre abril y septiembre, los pastores dormían solos en simples tiendas de lona, llevando su utillaje y provisiones en mulas o caballos de carga. Durante la estación invernal, la cubierta de tela era cambiada por unos remolques ("carrocampos"), tirados por machos y que quedaban más estables en un único lugar. En los periodos de entrada de los corderos y las ovejas viejas en los mercados se juntaban con el "mayordo-

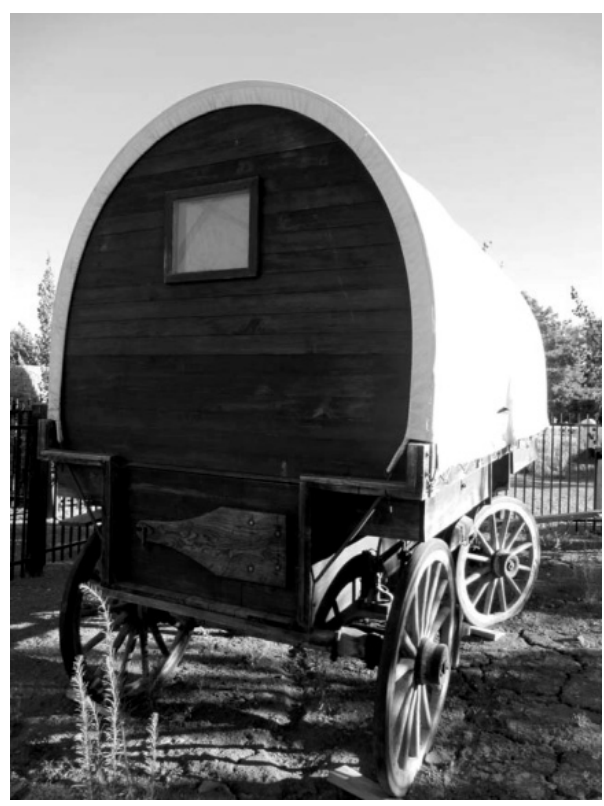

FIguRA 5.- "Carrocampo". Rancho San Rafael, Reno. 2010. Foto de Pablo Orduna Portús. 
mo" en unos corrales en la sierra para cargarlos en camiones y venderlos en Los Ángeles (CA). Tras la venta, juntaban varios atajos para pasar el invierno y se unían dos pastores en cada "carrocampo", y mientras uno hacía la intendencia, el otro cuidaba de las ovejas.

Otro momento de reunión era la castración de los corderos, que se efectuaba junto al "mayordomo" mediante la técnica de estirar y arrancar los testículos del animal con la boca. En ocasiones también se cruzaban con otros pastores si se juntaban en el monte cabezas

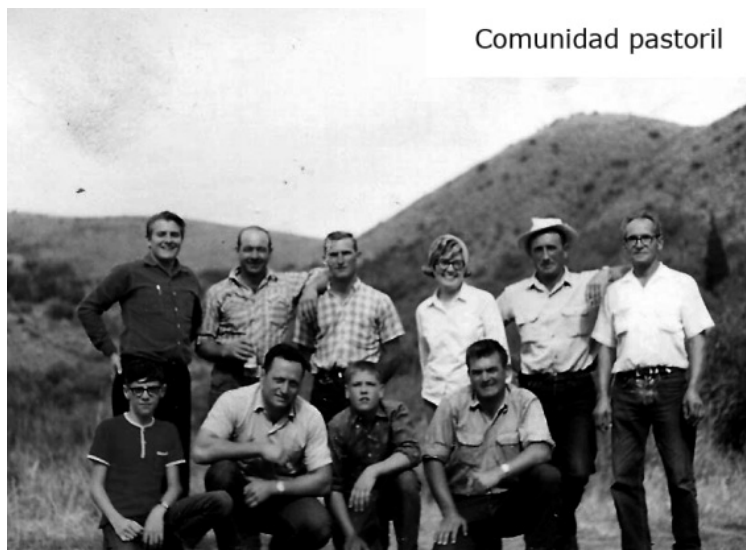

Figura 6.-Comunidad pastoril junto a Joxe MaellaOlaetxe. Nevada, años 60. Fondo fotográfico de Agustín de Miguel y Nicolás Pérez. de dos rebaños diferentes y había que separarlas. En el caso de coincidir en el verano dando sal sobre los bloques de piedra, también podían encontrarse momentáneamente con algún "campero" o el mayoral. De igual modo, en primavera volvían a verse varios pastores durante los periodos de esquileo, realizado por una compañía de Texas. En una ocasión, Joxe MaellaOlaetxe, entonces sacerdote, reunió a varios para celebrar una misa. En el grupo había uno sin confesar desde hacía más de diez años, preguntó a Maella si podía comulgar así y éste le respondió que bastante penitencia había cumplido en esos montes de soledad como para no poder hacerlo y que por ello él perdonaba los pecados a todos.

En el Medio Oeste y el más "lejano" Oeste norteamericano, la cría de ovejas se

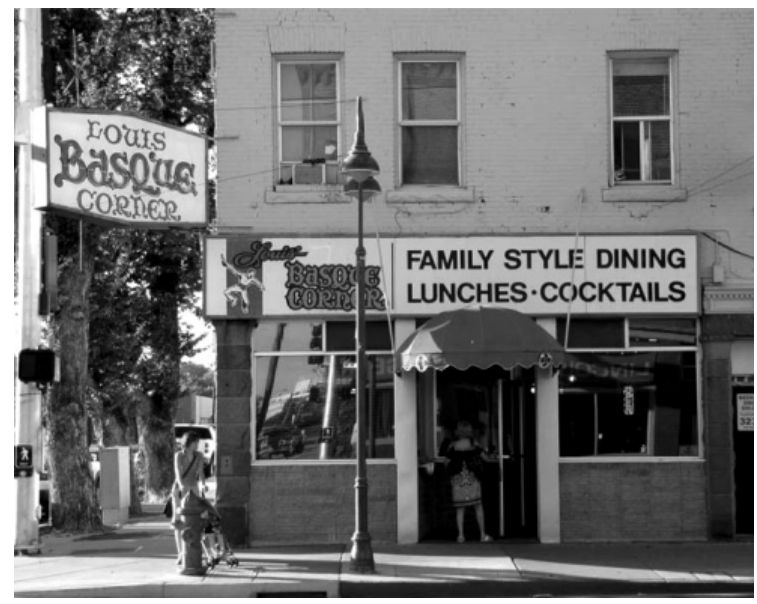

Figura 7.- Restaurante Louis' Basque Corner en Reno, Nevada. 2010. Lugar de encuentro de la comunidad vasca de la zona desde 1967. Foto de Pablo Orduna Portús. sustentaba en la red de boardingbouses - posadas o casas de huéspedes- localizada en los llanos, junto a las vías del tren en las poblaciones dispersas (Echeverria 1999). Durante los periodos de parición, conteo del ganado, de recogida del heno, etc., su localización era fundamental para la infraestructura de toda la industria (Totoricagüena 2004a: 61).

Estas pensiones, al situarse junto a las estaciones de tren o calles principales, se daban a conocer a los recién llegados, desconocedores del inglés (Douglass y Bilbao 1986). Aquellas en las que el dueño era de origen vascongado al principio eran llama- 
das ostatuak u hotelak por sus compatriotas y para ellos suponían el único sitio y momento donde se podía abandonar la ya mencionada solitude de los puertos y del desierto (Zubiri 1998: 30-32). Entre los más destacados, podemos citar en Elko el hotel Overland, donde se alojaron por primera vez nuestros dos pastores del Roncal.

Estos basque hotels servían como punto de encuentro de los pastores tras bajar de los campamentos de montaña. Además, eran utilizados como verdaderas instituciones donde los inmigrantes podían "culturizarse" en las costumbres y modos de vida sociales aún no familiares para ellos y conocer a gente originaria de Norteamérica y de otros grupos étnicos —anglo, indígena, etc.- (Totoricagüena 2004a: 47). Fueron el primer peldaño para la integración lejos de sus casas natales y de su mundo conocido hasta entonces.

\section{MODELO DE INTEGRACIÓN Y ASENTAMIENTO DEFINITIVO: "A SALAD BOWL".}

Con el tiempo, muchos de estos pastores recibieron visados de residencia permanente en los EE. UU y después pudieron solicitar permiso para traer a sus esposas e hijos. La Western Range Association logró, sólo en 1976, que 2.161 pastores vascos, principalmente vizcaínos y navarros, obtuvieran el permiso de residencia:

El planteamiento de estancia temporal se veía ampliado cada cierto tiempo [...], pero los años iban pasando y finalmente se perdía el sentido de la vuelta, a resultas de lo cual decidían establecerse permanentemente (Lasagabaster 2006: 72).

Hacia mediados de los años 70 ya no quedaban muchos en activo y los que quedaban estaban acabando su tercer y último año de contrato. Las condiciones económicas y políticas en Europa parecían mejorar y fue un momento de duras y vitales decisiones: regresar o quedarse definitivamente en suelo americano. En general, lo que era una norma común es que, una vez adquirido cierto dinero y estabilidad personal, muchos de ellos dejaban los rebaños para dedicarse a otro oficio o regresaban a su pueblo natal, abandonando su puesto de pastor en el Oeste (Douglass y Bilbao: 368). Un buen número solicitó la nacionalidad americana (citizenship) y buscó nuevas ofertas de empleo en otros sectores, sin aspirar a comprar propiedades y asegurarse pastos ante el United States Forest Service, como habían hecho sus predecesores de finales del XIX y principios del XX (Zubiri 1998: 290-294) ${ }^{13}$.

Si decidían quedarse, llegaba el problema de buscar un nuevo negocio y localizar un lugar fijo de asentamiento. Entonces, en cierto modo, un papel fundamental lo jugaron los Centros Vascos (euskal etxeak). No sólo trabajarían como mantenedores de la cultura del inmigrante, sino que abrieron a los miembros de su comunidad nuevas posibilidades para su integración y desarrollo en la sociedad de acogida. Así, sólo en Nevada existen cinco, y muchos más en los cercanos estados de California, Idaho, Colorado o Nuevo México (Lasagabaster 2006: 53 y 76).

Durante un verano de pastoreo en Nevada, Nicolás se introdujo en tierras de un

\footnotetext{
${ }^{13}$ A principios del siglo XX, de los inmigrantes vascos que residían en el Oeste norteamericano se naturalizaron sólo un 11,25\% y mantuvieron su estatus de extranjeros un 72,5\%, siendo desconocida la situación de otro 16,25\% (Bilbao 1982: 163 y ss.)
} 
rancho vaquero. El dueño intentó entenderse con él para decirle que saliera pero, como ni uno ni otro hablaban una lengua común, no hubo forma. El ranchero llamó a su hermano, jefe de policía en Pleasanton (California) que hablaba castellano. Éste, Walter McCloud, dialogando con nuestro roncalés, trabó amistad con él, además de conseguir que sacara las ovejas. Unas Navidades después le invitó a pasar las fiestas en su casa de California para presentarle a su familia. Allí, Nicolás le expuso la situación, tanto de su primo como suya, y el police chief le recomendó que, una vez acabado el contrato, fueran a la zona de la bahía de San Francisco. En esa área él conocía gente que podía darles trabajo y mejorar su vida. Un año después, los dos primos estaban trabajando para una empresa de construcción fundada por los hijos de unos vizcaínos exiliados de Lemoa durante la Guerra Civil Española. En dicha compañía trabajaron hasta retirarse, aunque también realizaron obras por su cuenta durante los fines de semana.

La llegada a California fue dura y gratificante a la vez, ya que supuso pasar de la absoluta soledad de los páramos de Nevada al bullicio de una urbe tan cosmopolita como San Francisco. Al llegar, McCloud les ayudó a arrendar un apartamento pequeño y comprar una ranchera. En este lugar vivieron junto con otro compañero pastor de Etulain (Valle de Anue, Navarra) hasta que se casaron. En 1972 Agustín lo hizo con una mujer chilena y Nicolás, en primeras nupcias, con una mexicana. Los familiares de Uztarroze no acudieron a las bodas, pero les enviaron los anillos desde Navarra y luego ellos fueron de visita al Valle. Una vez asentados en Fremont (CA) y Union City (CA), se relacionaron con gente de su entorno originario y con otros de fuera de él que les fue presentando el jefe de policía de Pleasanton. Para adaptarse mejor, acudieron a clases nocturnas de inglés. Ambos han observado que entre los hijos de los emigrantes se habla en inglés y entre estos y sus padres en castellano, o en euskara quienes lo saben. Finalmente, Agustín y Nicolás optaron por solicitar la ciudadanía americana en torno al año 1992.

En general, se puede definir diáspora como una población étnica dispersa y, en palabras de Oiarzabal (2005: 24), "desterritorializada que conforma una identidad colectiva en referencia siempre a la cultura dominante de sus países de residencia" ${ }^{14}$. Según este autor, este sentimiento de colectividad les ha llevado a crear instituciones y redes sociales sin solución de continuidad, y administraciones de cooperación invisibles fundamentadas en una idea de identidad y asentadas en diversos espacios geográficos. Sin embargo, no se han constituido en el sentido de guetos, sino que "lejos de ser monolíticas u homogéneas se integran en cada región de acogida" abriendo camino a sus miembros. Estas dinámicas — fundamentadas en el subizgu (hogar en uskara roncalés) y la familia- se basan en un entramado de formas de control social, cultural y corresponsabilidad derivada de las diferentes redes clientelares de alianza y parentesco, consaguinidad, hermandades y prácticas endogámicas reflejadas en la mentalidad familiar y comunitaria (Orduna 2004: 215).

Es cierto que una de las características más destacadas de estos inmigrantes res-

\footnotetext{
${ }^{14}$ Los vascos se asentaron en EE. UU bien individualmente o en grupos pequeños para dedicarse en su mayoría al pastoreo ovino. Esto impidió una concentración masiva en una zona o población concreta, por lo cual nunca se han llegado a convertir en el grupo étnico predominante en parte alguna (Douglass y Bilbao 1986: 29).
} 
pecto a la cultura del país de acogida es la distancia inicial. Esto provoca entendibles y en ocasiones complicados "choques de culturas" (Baxok 2006: 155). Douglass (1994: 13-17), que ha observado estos fenómenos, entiende al emigrante proveniente del mundo rural europeo como una "Víctima de la historia más que como a uno de sus arquitectos". Según él, estos campesinos deseaban huir de las penurias del campo y abandonar el pueblo en busca de la oferta de prosperidad que les hacía el mundo moderno y urbano. Sin embargo, la incomprensión de ese nuevo espacio cultural y la carencia de contactos en las ciudades les dirigen de nuevo al escenario agrario, lejos de su tierra.

En ese estado se ha hecho necesario asimilar un modelo de integración, una tipología de asimilación que ofertaba la sociedad receptora y a cuyos brazos debía arrojarse sin discusión alguna el recién llegado. En el caso de Estados Unidos, desde el siglo XIX hasta los atentados del 11 de septiembre de 2001, se desarrollaron tres fórmulas diferentes, tanto en sus pautas culturales, en su dimensión social, como en la propia valoración de la integración grupal. Blanco, recogido en el libro de Garreta y Llevot (2003: 25), las desglosa de la siguiente manera:

Evolución de los modelos de la integración de minorías étnicas en EE.UU.

\begin{tabular}{|l|l|l|l|l|}
\hline $\begin{array}{c}\text { Marco } \\
\text { temporal }\end{array}$ & \multicolumn{1}{|c|}{$\begin{array}{c}\text { Modelo de } \\
\text { integración }\end{array}$} & \multicolumn{1}{|c|}{ Pautas culturales } & Dimensión social & Identidad grupal \\
\hline Siglo XIX & $\begin{array}{l}\text { Anglo-conformity } \\
\text { [asimilación] }\end{array}$ & $\begin{array}{l}\text { Pérdida de las propias } \\
\text { pautas culturales y } \\
\text { asimilación total de las de la } \\
\text { sociedad de acogida } 15\end{array}$ & $\begin{array}{l}\text { Se produce una } \\
\text { inserción igualitaria. }\end{array}$ & $\begin{array}{l}\text { Pérdida de la propia } \\
\text { identidad } \\
\text { diferenciada y } \\
\text { sentimiento de } \\
\text { pertenencia a la } \\
\text { nueva sociedad. }\end{array}$ \\
\hline $1908-1950$ & Melting pot (crisol) & $\begin{array}{l}\text { Fusión de culturas } \\
\text { originarias y creación de una } \\
\text { nueva. }\end{array}$ & $\begin{array}{l}\text { Se da una inserción } \\
\text { igualitaria en una } \\
\text { nueva estructura. }\end{array}$ & $\begin{array}{l}\text { Surge una nueva } \\
\text { identidad colectiva. }\end{array}$ \\
\hline $1950-2001$ & $\begin{array}{l}\text { Salad bowl } \\
\text { (pluralismo) }\end{array}$ & $\begin{array}{l}\text { No se abandonan las pautas } \\
\text { culturales propias y se } \\
\text { aceptan las del lugar de } \\
\text { acogida sin desvirtuar las } \\
\text { primeras. }\end{array}$ & $\begin{array}{l}\text { Se logra una } \\
\text { inserción igualitaria } \\
\text { en la estructura } \\
\text { social que acoge al } \\
\text { migrante. }\end{array}$ & $\begin{array}{l}\text { Dualidad entre la } \\
\text { identidad originaria } \\
\text { y el logro de } \\
\text { pertenencia a la } \\
\text { comunidad } \\
\text { receptora. }\end{array}$ \\
\hline
\end{tabular}

No obstante, y tal como el propio Douglass (1994) reconoce, esta emigración transcontinental no tenía por qué conducir a una separación permanente con su entorno natal — —sorgüa" o lugar de nacimiento en el uskara roncalés—, aunque "Sea el

${ }^{15}$ Hay que matizar que un inmigrante vasco que llegaba a California a principios del XIX lo hacía a un lugar que formaba parte aun del imperio castellano (1769-1821). Con el tiempo, crecería o, al menos, conocería la California mexicana (1821-1848) para, finalmente, una vez establecido, criar a sus hijos como estadounidenses en un territorio integrado en la Unión (USA). Está claro que estos sucesos y devenires políticos afectaron seriamente a la integración de los inmigrantes. Se observa cómo los oriundos de Euskalerria, hasta al menos la segunda mitad del siglo XIX, no perdieron sus señas de identidad. Quizá esto se deba a que fuera muy difícil para ellos perderlas cuando la propia tierra de acogida (California) no estuvo siquiera del todo definida, por lo menos hasta el último tercio del Ochocientos. 
resultado más probable». Nuestros encuestados no olvidan su origen ronkaliar; incluso lo llegan a poner por delante de cualquier identidad española, europea, vasca o americana. Esto no significa que, como parte de una minoría, dejen de intentar incorporarse a la sociedad mayoritaria de acogida. De hecho, muestran su orgullo por participar activamente en ella y no sólo a nivel laboral, sino social, cultural o político. A la par, son capaces de retener el mosaico de aspectos más significativos de su propia idiosincrasia originaria, recalcando su identidad "con su propia escala de valores" (Douglass 1994: 34).

Optan por asimilar prácticas culturales de la sociedad que les acoge e integran partes o modos de éstas en las suyas propias. Este hecho les aporta bienestar emocional y psicológico (Basabe 2004: 136). Es decir, al igual que nuestros dos roncaleses, estos pastores de la segunda mitad del siglo XX estuvieron dispuestos a componer su propio cuenco de ensalada — Salad bowl-cultural en el Oeste de Norteamérica. Para ello aliñaron con sus propios valores tradicionales las nuevas sensibilidades y puntos de vista adquiridos lejos de su casa. El bertsolari Jesús Goñi, "Jess", describía este sentimiento común en unos versos recitados durante un festival vasco celebrado en Elko (NV) y transcritos por Maella-Olaetxe (2003: 204):

\author{
Amerikarat etorri ginan \\ Euskal Herri maite hartik \\ Eta Amerikan oraindik ere \\ Gure obiturak bizirik \\ Dantzan eginez, harrijasotzen \\ Llegamos a América \\ Desde nuestro amado País Vasco \\ Y todavía en América siguen \\ vivas nuestras tradiciones \\ Danzando y levantando piedras
}

\section{Aizkolariak berdinik \\ Bertsutan ere jarraitzen degu \\ Orain Euskadiko aldetik \\ Urrenguak'e izan dezaten \\ Gure gustua ondotik [bis]}

Lo mismo con los aizkolaris También continuamos improvisando versos De modo

que quienes vengan después nuestra

También puedan disfrutar las mismas cosas que hacemos.

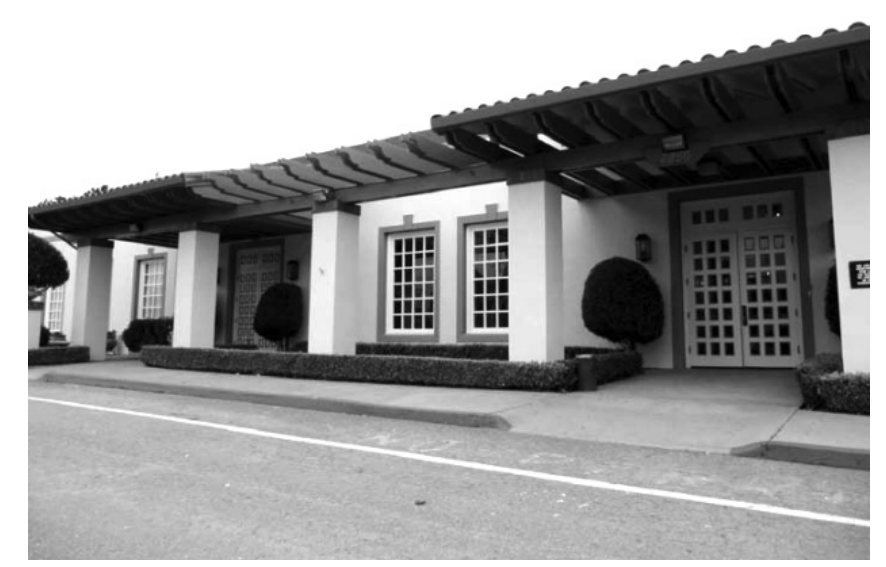

Figura 8.-Unión Española de California, San Francisco. 2010. Foto de Pablo Orduna Portús. 
Ahora bien, debemos entender el concepto de etnia como una amalgama, un sistema de conductas y comportamientos vinculados a un grupo, unidos a éste en base al factor etiológico de la solidaridad que queda sustentado en un mismo sentimiento de identidad y pertenencia comunitaria (Irujo 2012; Douglass 1994: 65) ${ }^{16}$. Sentimiento que no es sino el reflejo de una adscripción e identificación de uno mismo en un contexto nuevo y diferenciador (Totoricagüena 2004b: 1; Barth 1969: 10). En palabras de Lisa M. Corcostegui (1999: 250):

Ethnic identity involves a group's emblematic use of various aspects of culture in order to differentiate itself from other groups. Tangible aspects which are often recognized as symbols or emblems of ethnic identity are language, clothing and food.

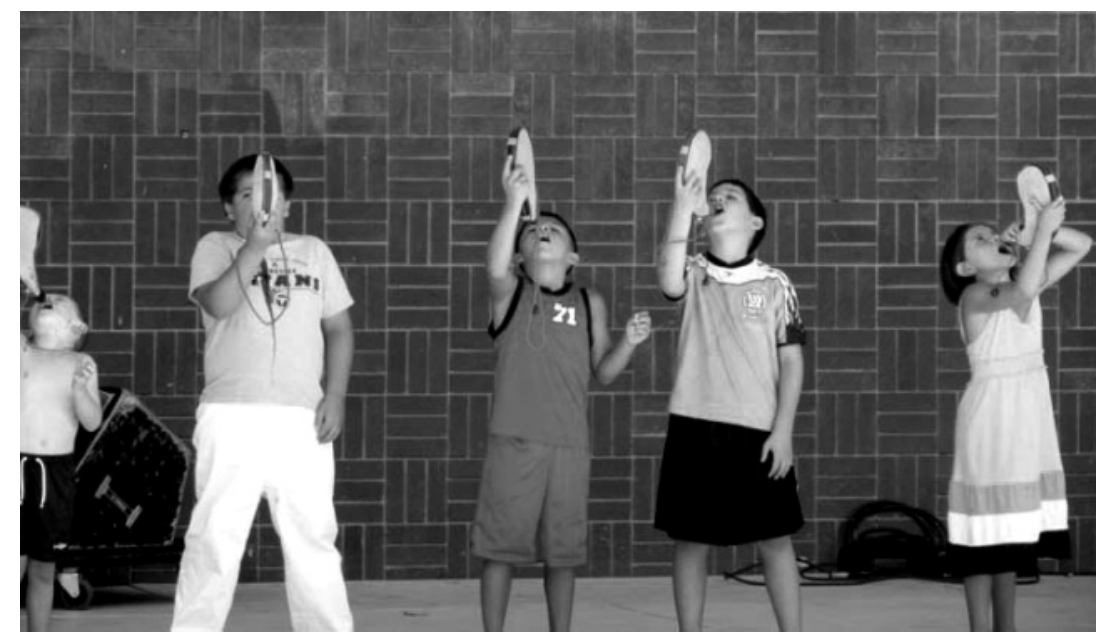

Figura 9.-Concurso de bebedores de bota de vino en el Basque Festival de Reno. 2010. Foto de Pablo Orduna Portús.

El contingente inmigrante contribuye de forma esencial al enriquecimiento de la sociedad de acogida; da pie a una mayor diversidad cultural en su seno, trasformando las distintas identidades y desdibujando las fronteras tradicionales (Oke 2004: 9). Agustín y Nicolás no dejan de acudir a la San Fermin Celebration de la Unión Española de la Bahía de San Francisco o a los eventos festivos del Basque Cultural Center de la misma región. Además mantienen relaciones con el Zazpiak Bat Basque Club de Reno (NV) y han acudido en alguna ocasión a su festival vasco veraniego. En este evento pude observar un ejemplo de reinterpretación de la tradición en el concurso infantil de bebedores de bota de vino: varios niños participaban bebiendo un zumo y quien menos se manchaba y con más estilo bebía, ganaba. Se trata de una nueva reinterpretación de la tradición, una praxis de la cultura, una autoafirmación en la diferencia. En definitiva, han sabido adaptar de forma consciente a su sociedad ac-

\footnotetext{
${ }^{16}$ Además, hay que señalar que la lengua común (el euskara en este caso) ha sido siempre un elemento más de este proceso de integración del individuo en su etnia, y de consolidación de las redes de alianzas que ésta genera.
} 
tual aquellos elementos procedentes de su herencia cultural y que han entendido como dignos de conservar. Se ha tratado de una convergencia cultural dinámica e híbrida por definición, propia del mundo contemporáneo, en la cual «el presente contiene el pasado" (Martí 1996: 214).

\section{A MANERA DE CONCLUSIÓN: DINA ABAÑO DINA URRIN}

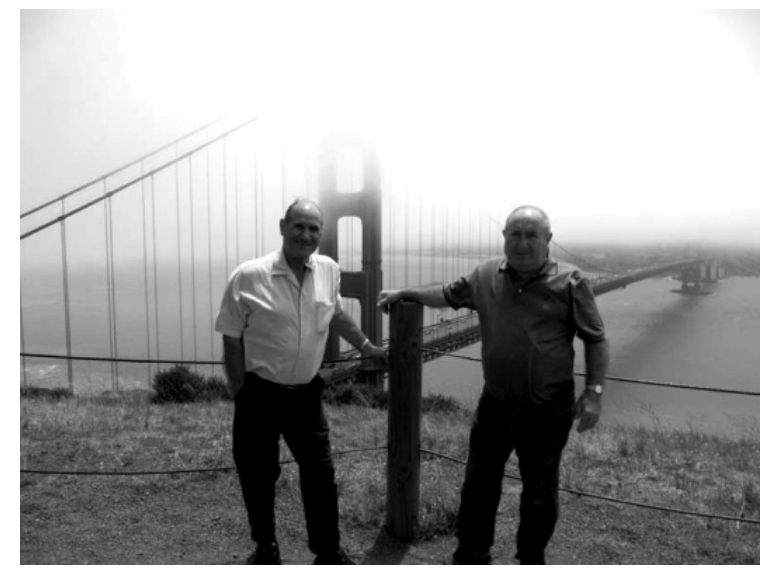

Figura 10.-Nicolás y Agustín junto al Golden Gate de San Francisco. 2010. Foto de Pablo Orduna Portús. dice en roncalés para referirse a aquello que, estando cerca, consideramos lejano y en cambio a lo que siendo lejano, sentimos cerca. Esa es la sensación cuando nuestros dos encuestados hacen referencia al pasado en su valle del Pirineo. Sin embargo, al mismo tiempo se observa cómo forman parte de un colectivo migrante ya asentado que es capaz de mantener una sincera lealtad, tanto a su cultura originaria, como a la que les ha acogido. De hecho, su propia identidad ha mutado y se ha hecho algo muy complejo. Nuestros dos actores principales han sabido conjugar sus distintos "ser", elaborando en su personalidad un mosaico de rasgos culturales roncaleses, americanos, vasco-navarros e hispanos; engranaje donde no se encuentra confrontación alguna y sí una gran variedad de recursos sociales que han permitido su completa adaptación en el seno de la poco estable y permeable Anglo society estadounidense.

Douglas y Bilbao (1986: 394) aseguran que, al regresar a sus terruños natales, muchos de estos emigrantes llegaban a sufrir la presencia de aquellas imágenes fijas de sus familias, amigos y entorno originario; estampas que ellos habían mantenido congeladas de forma inalterable en su memoria y que, a su regreso, veían cambiadas, dificultando cualquier intento de reinserción colectiva. Nuestros protagonistas tardaron un tiempo en volver y obviamente su pueblo y valle habían cambiado. Les asombró observar mayores servicios, casas rehabilitadas, calles con el empedrado reparado y que los jóvenes, aunque marchándose aún en gran medida, tenían mejores expectativas más cerca de su propia tierra (Pamplona, Aoiz, Sangüesa, San Sebastián, etc.).

Muchos decidieron quedarse en su nueva tierra. Los dos Uztarroztarras se sienten ya parte de América, aunque no olvidan su origen y en su pueblo natal se sienten uno más. El deseo de vuelta definitiva ha desaparecido ya. A finales de los 70, ambos veían acabarse este mundo ganadero en Norteamérica. De hecho, hoy en día, se pueden dar casi por finalizados los últimos capítulos del pastoreo en el Oeste. Para ellos supuso su mejor opción de vida y ahora es parte del recuerdo. Zubiri (1998: 22-23), en su Travel guide to Basque America, hacía mención a la paradoja, observada por mí mismo, de ver cómo en los restaurantes vascos de aquellos estados se sirve cordero elaborado según recetas tradicionales. Ahora 

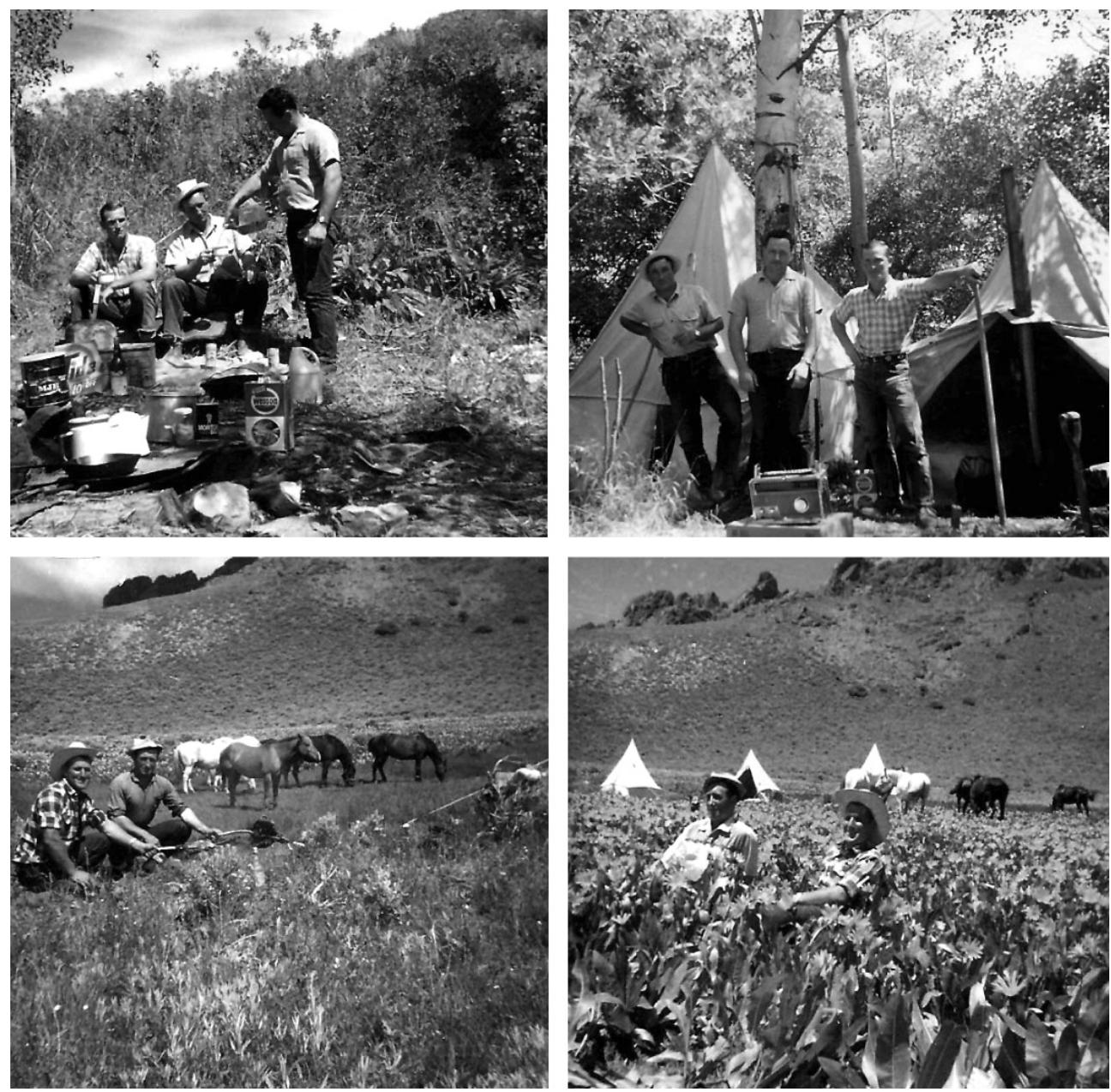

FIgURA 11.-Ambos roncaleses junto al etulaindarra en los campamentos estivales. Nevada, años 60. Fondo fotográfico de Agustín de Miguel y Nicolás Pérez.

bien, la carne ya no proviene de los pastos del Great Basin, sino que es importada de Nueva Zelanda o Australia.

En general, se puede clasificar a la colectividad pastoril vasca del Oeste norteamericano como una diáspora, ya que, como afirma Cohen (1997: 180), sufrieron su propia dispersión del país de origen, buscando nuevas oportunidades económicas, manteniendo una memoria colectiva e idealizando su tierra natal. A pesar de haber existido ciertos movimientos de retorno, se mantiene una fuerte identidad "étnica", incluso ante ciertas problemáticas de adaptación en su país de acogida, con gran sentimiento de solidaridad interno y expectativas de una vida mejor en su nuevo espacio de asentamiento. Por ejemplo, los propios encuestados no dudaron en dar alojamiento en el área de San Francisco a un antiguo compañero pastor en Nevada, que había venido 
desde Etulain (Valle de Anue, Navarra), y venderle a buen precio su ranchera común cuando se compraron sus propios coches particulares.

Por lo tanto, podemos clasificar a esta colectividad pastoril del Oeste norteamericano como un grupo visiblemente cohesionado con unas características comunes. Todos sus miembros han sufrido su propia dispersión del país de origen y un distanciamiento originado por la búsqueda de nuevas oportunidades laborales que no les ha impedido mantener una memoria colectiva. Un ejemplo de este carácter de hermandad ha sido el sentimiento de solidaridad y obligación de asistencia mutua - anaitasuna ta beharra - ante cualquier problemática de adaptación al país de acogida.

\section{BIBLIOGRAFÍA CITADA}

Alday, A. 1999. "Vasco-navarros en el Nuevo Mundo: Una identidad dual", en W. A. Douglass et al., The Basque diáspora: 150-173. Reno: University of Nevada.

Axular, P. 2003. Gero. Pamplona: CAN.

Barandiarán, J. M. 1953-1957. "Aspectos sociográficos de la población del Pirineo Vasco". Eusko Jakintza 7: 3-26.

Barandiaran, J. M. y Manterola, A. (dirs.). 2000. Atlas Etnográfico de Vasconia. 11, Ganadería y pastoreo en Vasconia. Bilbao: Etniker Euskalerria.

Barth, F. 1969. Ethnic groups and boundaries. The social organization of culture difference. Londres: George Allen and Unwin.

Basabe, N. et al. 2004. Integración socio-cultural y adaptación psicológica de los inmigrantes extranjeros en el País Vasco. Vitoria-Gasteiz: Gobierno Vasco.

Baxok, E. et al. 2006. Identidad y cultura vascas a comienzos del siglo XXI. San Sebastián: Eusko Ikaskuntza.

Bilbao, I. 1982. Información sobre posibles vascos contenida en los censos de población de 1900 de los estados de Arizona, Colorado, Idaho, Montana, Nevada, Nuevo México, Oregón, Utah, Washington y Wyoming de los Estados Unidos de América. Vitoria- Gasteiz: Diputación Foral de Álava.

Campbell, J. 1973. The hero with a thousand faces. New Jersey: Princeton University Press.

Ciérbide, R. 1997. Vasconavarros en el oeste americano. Memorias de un viaje y otras historias. Tafalla: Imprenta Ainzúa.

Cohen, R. 1997. Global diasporas: An Introdution. Londres: University College Press.

Corcostegui, L. M. 1999. "Moving emblems. Basque dance and symbolic ethnicity", en W. A. Douglass et al., The Basque diaspora: 249-273. Reno: University of Nevada.

Douglass, W. A. et al. 1994. Migración, etnicidad y etnonacionalismo. Bilbao: UPV-EHU.

Douglass, W. A. y Bilbao, J. 1986. Amerikanuak: los vascos en el Nuevo Mundo. Leioa: UPV-EHU.

Douglass, W. A. y Lane, R. H. 1985. Basque Sheep Herders of the American West. Reno: University of Nevada Press.

Echeverria, J. 1999. Home Away from Home: A History of the Basque Boardinghouses. Reno: University of Nevada Press.

Garreta, J. y Llevot, N. 2003. El espejismo intercultural. La escuela de Cataluña ante la diversidad cultural. Madrid: Ministerio de Educación, Cultura y Deporte, CIDE.

Georgetta, C. 1972. Golden Fleece in Nevada. Reno: Venture Pub. Co.

Irujo, X. 2012. On basque Politics. Conversations with Pete Cenarrusa. Bruselas: EURI.

Lane, R. H. 1977. "Trouble in the Sweet Promised Land: Basques in Early 20th Century Northeastern Nevada", en W. A. Douglass et al., Anglo-American contributions to Basque studies, essays in honor of Jon Bilbao: 33-41. Reno: Desert Research Institute.

Lasagabaster, D. 2006. Las lenguas de la diáspora vasca en el Oeste de los Estados Unidos. Pamplona: Lete Argitaletxea. 
Laxalt, R. 1957. Sweet Promised Land. Nueva York: Harper.

Mallea-Olaetxe, J. 2000. Speaking Through the Aspens: Basque Tree Carvings in California and Nevada. Reno: University of Nevada Press.

Mallea-Olaetxe, J. (ed.). 2003. Shooting from the lip: "bertsolariak ipar amerikan": improvised Basqueverse singing. Reno: North American Basque Organization.

Martí, J. 1996. El folklorismo. Uso y abuso de la tradición. Barcelona: Ronsel.

Oiarzabal, A. et al. 2005. La identidad vasca en el mundo. Bilbao: Erroteta.

Oke, O. B. 2004. "Presentación", en N. Basabe et al., Integración socio-cultural y adaptación psicológica de los inmigrantes extranjeros en el País Vasco: 1-10. Vitoria-Gasteiz: Gobierno Vasco.

Orduna, P. 2004. "Estudio etnológico del hogar en el Valle de Roncal". Cuadernos de Etnología y Etnografía de Navarra 79: 211-278.

Paris, B. 1971. Beltran: Basque Sheepman of the American West. Reno: University of Nevada Press.

Pérez de Arenaza, J. Ma . et al. 1991. Euskal presentzia Ameriketan. Vitoria-Gasteiz: Gobierno Vasco.

Sawyer, B. W. 1971. Nevada Nomads. San Jose: Harlan Young Press.

Totoricagüena, G. 2003. "Ethnic Industries for Migrants: Basque Sheepherding in the American West". EuskoNews and Media 212: http://www.euskonews.com/0212zbk/frkosmo.htm

Totoricagüena, G. 2004a. Boise Basques: dreamers and doers. Reno: Center for Basque Studies, University of Nevada.

Totoricagüena, G. 2004b. Identity, culture, and politics in the Basque diaspora. Reno: University of Nevada Press.

Urrutia, T. 1992. El roble y el ombú. Viaje a la América de los vascos. Vitoria-Gasteiz: Gobierno Vasco.

Zubiri, N. 1998. A travel guide to Basque America: families, feasts, and festivals. Reno: University of Nevada Press.

Fecha de recepción: 6 de mayo de 2011

Fecha de aceptación: 20 de marzo de 2012 